\title{
RESEARCH OF MECHANICAL TREATMENT INFLUENCE ON RHEOLOGICAL PROPERTIES OF COAL-WATER FUEL BASED ON LOW- GRADE 3B COAL
}

\author{
A. A. Tolokolnikov ${ }^{1,}$, S. A. Yankovsky ${ }^{1,}{ }^{*}$, V. E. Gubin V.E. ${ }^{1}$, A. V. Zenkov ${ }^{1}$ and A. S. \\ Zaitsev $^{1}$ \\ ${ }^{1}$ Tomsk Polytechnic University, 634050, Tomsk, Russia
}

\begin{abstract}
Experimental study of mechanical treatment effect of rotary flow modulation device on coal-water fuel rheological properties were conducted. The slurry was prepared on the basis of low-grade 3B coal from Balakhtinskoe deposit.
\end{abstract}

\section{Introduction}

Energy Development Strategy of Russia [1] involves the widespread use of solid fuels in energy production by direct combustion at thermal power plants. The main consumer of high-grade coal is the steel industry due to its technological features at the expense of other energy objects [2-5].

It is known [2] that the variety of thermal power stations operate on non-projected fuel, often with low thermal parameters, which leads to serious problems, especially during peak load of boilers [2-5].

At nowadays, there is a prospective technology of low-grade coal application in energy sector [6], so called coal-water fuel [6]. This technology represents composite dispersed system consisting of a solid phase in the form of finely divided coal, liquid medium (water) and plasticizing agent [6]. Research in this area is urgent due to the fact that there is no scientifically sound procedural framework describing physical and chemical processes in CWF.

\section{Experimental setup and study technique}

Experimental studies were conducted on 3B brown coal from "Balakhtinskoe" deposit.

The initial coal samples were sieved through a sieve with a mesh size of 80 microns after primary treatment. After that, the obtained material was milled in a ceramic drum of 2 liter volume with distilled water and grinding bodies for 1.5 and 9 hours. The weight ratio of researched coal and water are shown in Table 1 . The obtained slurry was subjected to further treatment in a rotary flows modulation device (RFMD) after reaching a given

* Corresponding author: Jankovsky@tpu.ru 
milling time. RFMD was included in the CWF preparation scheme to improve its rheological properties. Density and dynamic viscosity were determined after the treatment by Brookfield viscometer. Experiments to determine fuel sedimentation stability after 24 hours were performed with the use of beakers.

The percent-mass concentrations of the examined CWF samples are presented in Table 2.

Table 2. Examined CWF compositions.

\begin{tabular}{|c|c|c|}
\hline Sample name & Mass content of coal, $\%$ & Mass content of water, $\%$ \\
\hline \multirow{3}{*}{$3 B$} & 48 & 52 \\
\cline { 2 - 3 } & 45 & 55 \\
\cline { 2 - 3 } & 42 & 58 \\
\hline
\end{tabular}

\section{Experimental results}

As a result of a series of experiments, the dependencies presented in Figures 1-2 were obtained.

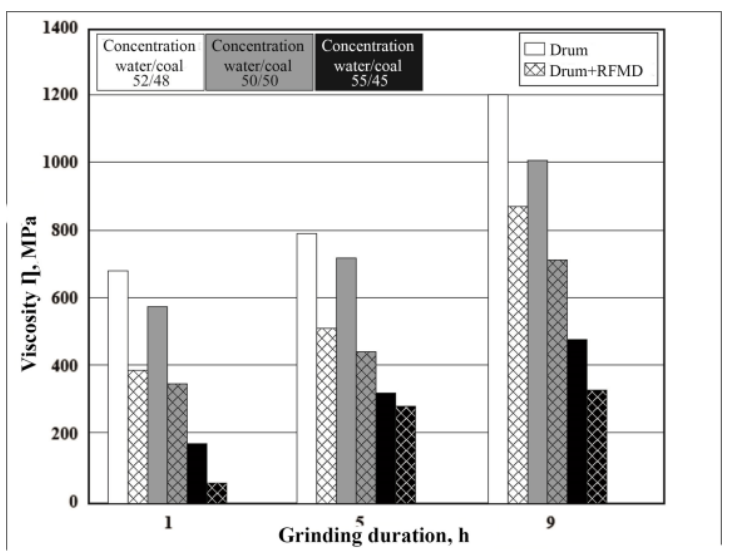

Fig. 1. Dependence of CWF viscosity based on 3B coal from grinding duration and concentration composition at a given sliding velocity of viscometer.

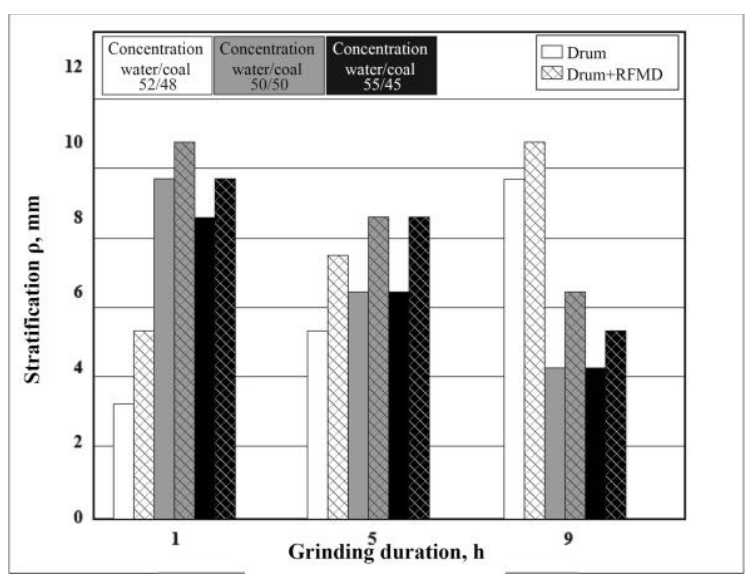

Fig. 2. Effect of grinding time on CWF sedimentation stability for 3B grade coal. 
Analysis of the obtained results showed a decrease in samples viscosity due to the dispersion of the solid part in coal-water fuel because of the acoustic, hydrodynamic and mechanical impact of the rotary flows modulation device.

CWF sedimentation stability is worsened as a consequence of more active particulate solids precipitation than before mechanical treatment.

\section{Conclusion}

Results of the conducted research revealed that the use of rotary flows modulation device reduces coal-water fuel viscosity and increases its sedimentation stability.

The work has been supported by the Russian Federal focused program "Research and development on priority orientation of science and technology in Russia 2014-2020", unique identifier 'Applied Research and Experimental Developments' project RFMEFI58114X0001.

\section{References}

1. B. Vorobyev, Herald of the Russian Academy of Sciences 1, 65 (2011)

2. T. Taylasheva, A. Gil, E. Vorontsova, Bulletin of the Tomsk Polytechnic University 327, 128 (2016)

3. M.P. Baranova, V.A. Kulagin. Fiziko-himicheskie osnovi polucheniya toplivnih vodougolnih suspenziy: monografiya (Sibirskiy federalniy universitet, Krasnoyarsk, 2011) [in Russia]

4. A.G. Korotkikh, K.V. Slyusarskiy, MATEC Web of Conf. 23, 01020 (2015)

5. S. Jankovskiy, D. Luzhkovoj, K. Larionov, A. Matveeva, MATEC Web of Conf. 37, 01026 (2015)

6. A.V. Zenkov, Yankovsky, S.A. Matveeva, S.V. Lavrinenko, A.A. Gromov, MATEC Web of Conf. 72, 01131 (2016) 